\title{
Control and Sizing of a Hybrid Battery and Compressed Air Energy Storage system
}

\author{
Phaisan Omsin \\ Mechanical Engineering, \\ University of Southampton \\ Southampton, UK \\ po1e13@soton.ac.uk
}

\author{
Suleiman M. Sharkh \\ Mechanical Engineering, \\ University of Southampton, \\ Southampton, UK \\ S.M.Sharkh@soton.ac.uk
}

\author{
Mohamed Moshrefi-Torbati \\ Mechanical Engineering, \\ University of Southampton, \\ Southampton, UK \\ M.M.Torbati@soton.ac.uk
}

\begin{abstract}
This paper discusses the sizing and control of a hybrid energy storage system comprising a battery and a compressed air energy storage (CAES) system. The CAES system is connected to the load through a boost converter that controls the air motor's speed to achieve maximum power point tracking (MPPT). A bidirectional converter is used to connect a battery to the load and maintain the output voltage constant. The air motor and battery sizes are estimated for a typical house in the Southern region of the UK. The battery is sized to buffer load fluctuations. All system models have been simulated using MATLAB/Simulink. Two scenarios are considered: a CAES only system controlled in constant voltage mode and a hybrid system comprising CAES with an MPPT controller and a battery with a voltage controller. The results demonstrate that the power rate of air motor is estimated properly by considering the difference between the generated power and demand power. The power difference called energy deficit is used to size the battery. The performance of CAES system is improved by hybridizing with a battery; the system maintains constant voltage when the CAES operates at maximum power point (MPP). The air motor in hybrid system controlled in MPPT mode has approximately $47 \%$ greater efficiency than that of air motor controlled in voltage mode.
\end{abstract}

Keywords-Energy deficit, hybrid energy storage system, MPPT controller, sizing, voltage controller

\section{INTRODUCTION}

The use of renewable energy sources has increased significantly worldwide [1]. Renewable energy sources, however, are intermittent in nature, which together with power demand fluctuations can lead to instability of the electrical supply. These reasons have resulted in the growth of interest in alternative energy storage systems (ESS) as options for storing excess energy and using it later when the demand is greater than generation. Several types of ESS such as flywheels, pumped hydro, compressed air energy storage (CAES), supercapacitors and batteries have been introduced and integrated within electricity networks [2], [3]. The CAES system is interesting because it has the potential benefits of having a small environmental footprint with ease of maintenance and recyclability [4]. Both small and large scale CAES systems have been intensively investigated [1], [5]-[8]. Maximum efficiency point tracking (MEPT) and maximum power point tracking (MPPT) strategies have been used in electronic control systems for small-scale CAES (SS-CAES) systems [4], [9]. A recent study on MPPT described a hybrid perturb and observe (P\&O) method, which provides good system performance for real-time tracking of maximum power [4]. The CAES, however, is slow to react to electrical load changes because it is a mechanical system. It also has a very narrow maximum efficiency peak and a significant drop of efficiency results from a small deviation from the MEPT/MPPT (efficiencies of MEPT and MPPT strategies are close to each other; the MPP efficiency is $1 \%$ lower than that

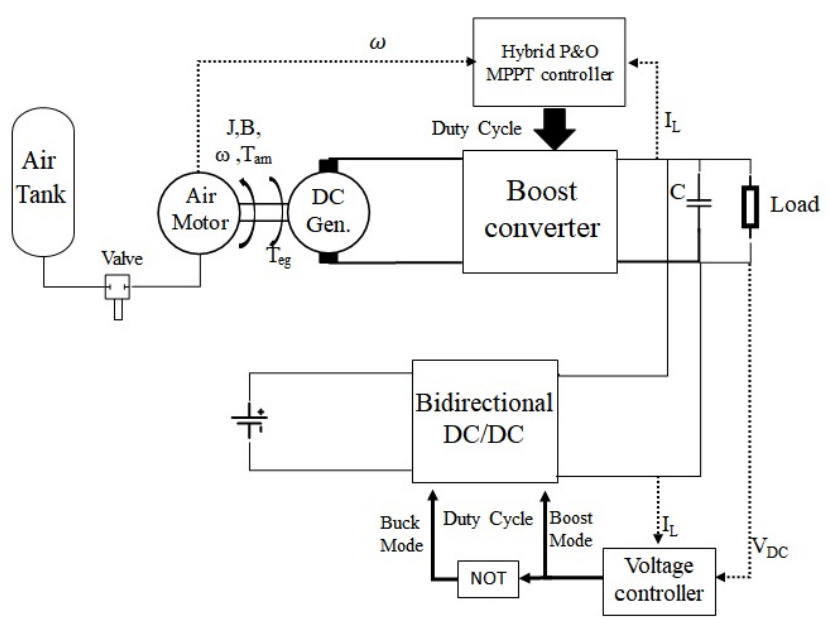

Fig.1 Configuration of the hybrid ESS with controllers

of the MEP). However, MPPT is easier to implement than MEPT [4].

In this paper, a hybrid SS-CAES with a battery and its controllers are proposed to supply a constant voltage to a variable dc load. The battery can resolve the CAES issues mentioned above by buffering load fluctuations while the SSCAES operates at its the MPP. Moreover, a method for sizing the battery and CAES air motor is proposed to ensure that the system supply sufficient energy to meet the demand.

\section{MODELLING}

\section{A. System Configuration}

Fig. 1 shows the configuration of the proposed hybrid storage system, which is connected to a variable dc load. The CAES is connected through a boost converter to the load while the battery is connected in parallel through a bidirectional dc/dc converter. The overall power management strategy is based on operating the CAES at its maximum power point (which is close to its maximum efficiency point) [4], by controlling the output current of its $\mathrm{dc} / \mathrm{dc}$ boost converter. The voltage of the dc load is kept constant by the battery and the buck-boost converter, which charges the battery if the CAES power is greater than load demand and discharges it otherwise.

\section{B. CAES and Boost Converter}

The CAES system has three significant components, namely, the storage tank, air motor and the dc generator connected to a boost converter. The characteristics of the air motor LZB 14 AR034 (100W) [10] are used in this work; they are scaled appropriately to change the operating pressure and output power. The important model characteristics for simulation such as the torque $\left(T_{a m}\right)$, air consumption $\left(\dot{V}_{a}\right)$ and power $\left(P_{a m}\right)$ are derived using curve fitting of the characteristics provided in manufacturer's datasheet, which are given by: 


$$
\begin{aligned}
& T_{a m}=T_{0}\left(p_{i}\right)\left(1-\frac{\omega}{\omega_{\text {ro }}}\right) \\
& P_{a m}=\omega \cdot T_{a m} \\
& \dot{V}_{a}=\dot{V}_{\text {max }} \exp \left(-\left(\frac{\omega-c_{1}}{c_{2}}\right)^{2}\right)
\end{aligned}
$$

where $T_{0}\left(p_{i}\right)$ is the stall torque at the specific pressure, $\omega$ is the air motor speed, $\omega_{\text {ro }}$ is the free speed of the air motor, $\dot{V}_{\text {max }}$ is the maximum air consumption [4]. $c_{1}$ and $c_{2}$ are the real constants what are estimated from the performance of the air motor. The permanent magnet dc (PMDC) generator is connected to the boost converter. The dynamic behavior of the PMDC generator is expressed by:

$$
T_{a m}-k_{e} i_{a g}=B_{t} \omega+J \frac{d \omega}{d t}
$$

where $k_{e}$ is torque constant of the generator, $i_{a g}$ is its armature current, $B_{t}$ is the viscous friction coefficient and $J$ is the moment of inertia of the air motor and generator [4]. The parameters of the $24 \mathrm{~V}$ dc generator used in this study as the input voltage for the converter are shown in table I. The equivalent circuit of the dc generator with boost converter is shown in Fig. 2. The current output of the boost converter is controlled by adjusting the duty cycle ' $\mathrm{D}$ ' of the transistor. The state-space averaged equations are employed to model the converter under continuous mode condition; that can be expressed as:

$$
\begin{aligned}
& \frac{d i_{L}}{d t}=-\frac{r_{a g}}{L_{t}} i_{L}-\frac{D^{\prime}}{L_{t}} v_{C}+\frac{V_{i n}}{L_{t}} \\
& \frac{d v_{C}}{d t}=\frac{D^{\prime}}{C} i_{L}-\frac{1}{R C} v_{C} \\
& v_{o}=v_{C}
\end{aligned}
$$

where $D^{\prime}=1-D$ and $L_{t}=L+L_{a g}$.

Since the CAES connected with boost converter is controlled by the MPPT controller, the PI controllers were tuned using state-space averaged models.

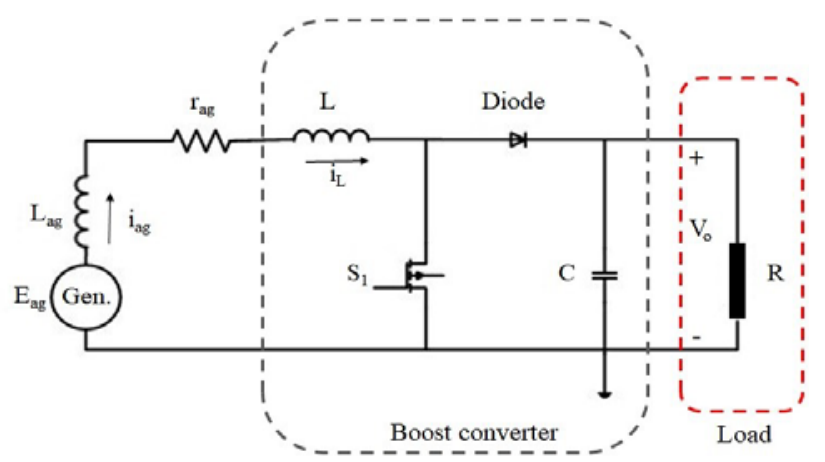

Fig.2 PMDC generator with a boost converter

\section{Battery and Bidirectional Converter}

The battery is used to compensate for insufficient supply power. In addition, it stores excess power from the CAES as well as handling fast load fluctuations. A Li-ion battery is chosen in this study, the model of which is available in

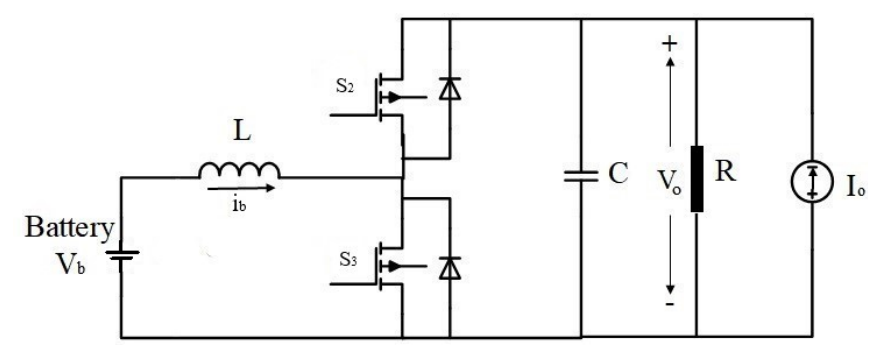

Fig.3 Battery with a bidirectional converter

SimPowerSystems of Simulink [11]. The circuit diagram of the battery with the bidirectional converter connected to the dc load is shown in Fig. 3. The battery discharges when the demand is greater than the generated power (the switch $\mathrm{S}_{3}$ is activated while the switch $\mathrm{S}_{2}$ is always open) and charges where there is excess power (the switch $\mathrm{S}_{2}$ is activated while the switch $\mathrm{S}_{3}$ is always open). The state-space average equations for the converter under continuous condition are:

$$
\begin{aligned}
& \frac{d i_{L}}{d t}=-\frac{D^{\prime}}{L} i_{L}+\frac{V_{\text {in }}}{L} \\
& \frac{d v_{C}}{d t}=\frac{D^{\prime}}{C} i_{L}-\frac{1}{R C} v_{C}+\frac{I_{O}}{C} \\
& v_{o}=v_{C}
\end{aligned}
$$

The PI controllers were tuned based on the state-space averaged model.

\section{CONTROLLER DESIGN}

\section{A. MPPT Controller for CAES}

A MPPT speed controller is designed for the CAES. In this paper, $\mathrm{P} \& \mathrm{O}$ method is applied to extract maximum power from CAES, which operates by sensing the torque $\left(T_{a m}\right)$ calculated from (1) and the air motor speed $(\omega)$. The MPPT controller regulates the speed operating point of the air motor in order to reach the MPP. Fig. 4 depicts the control scheme of CAES with a boost converter. Here, the converter is controlled by two cascaded PI controllers: an outer speed control loop that sets the reference for an inner current control loop. The speed of the air motor $(\omega)$ is sensed and compared with the MPPT speed reference $\left(\omega_{\text {ref }}\right)$ to calculate the error. This speed error is then used by a PI controller to set the current reference $\left(I_{\text {ref }}\right)$. The CAES current $\left(I_{L}\right)$ will track this reference value and the duty cycle for the converter is produced accordingly.

The flow chart of the MPPT controller based on [12] is shown in Fig. 5. Torque and speed values are measured and used to compute the change of power, duty cycle and speed. If the power difference is positive and the duty cycle difference is negative, then the reference speed will be increased by an amount of $\Delta \omega$, and if both these differences are positive, then the reference speed will be decreased by the same amount.

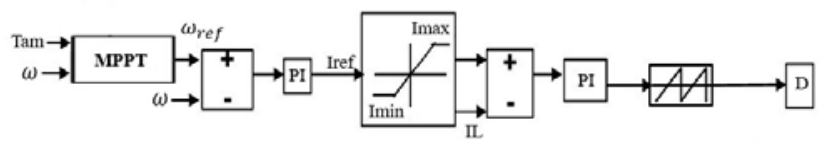

Fig.4 Modelling of SS-CAES controller 


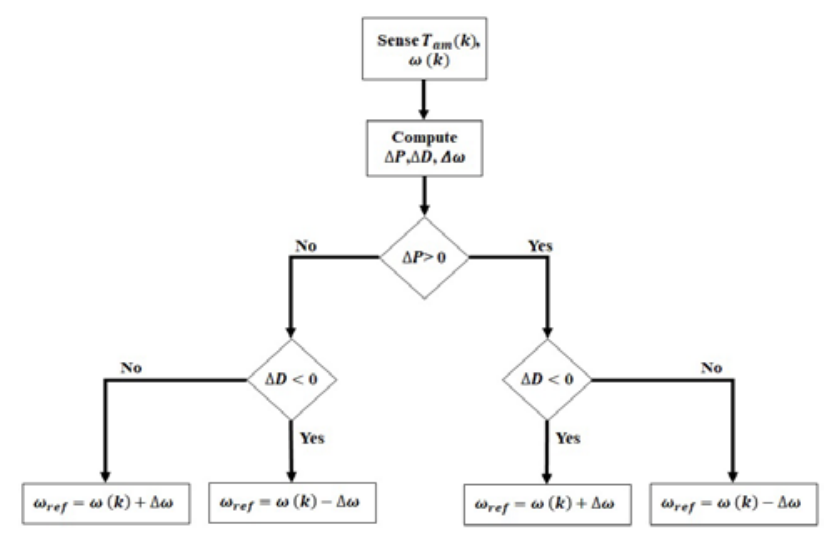

Fig.5 MPPT flowchart

On the other hand, if the differences in power and duty cycle values are negative, then the reference speed will be decreased, and if the differences in power is negative and the duty cycle positive, then the reference speed will be increased.

\section{B. Voltage Controller for CAES}

A voltage controller is designed for the CAES connected to a boost converter. Fig. 6 illustrates the block diagram of the CAES voltage controller. The voltage $\left(V_{\text {bus }}\right)$ is detected and compared with the voltage reference $\left(V_{\text {ref }}\right)$. The error between these two values is applied to a PI controller, which generates the current reference $\left(I_{\text {ref }}\right)$ of the inner loop. The CAES current $\left(I_{L}\right)$ will be regulated to its reference value $\left(I_{\text {ref }}\right)$ by the PI controller. The duty cycle, which is the output signal, is then generated accordingly. Due to the output voltage being kept constant by this controller, the air motor speed will be varied in order to generate the current to load demand.

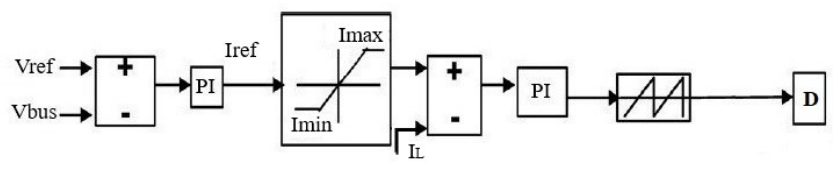

Fig.6 Modelling of CAES voltage controller

\section{Battery Controller}

A voltage controller is designed for the battery such that the bidirectional converter absorbs and delivers transient power during power fluctuation while the output voltage is kept constant. Fig. 7 illustrates the block diagram of the battery controller. The voltage $\left(V_{\text {bus }}\right)$ is measured and compared with the voltage reference $\left(V_{\text {ref }}\right)$. This error is minimized by a PI controller, which sets the current

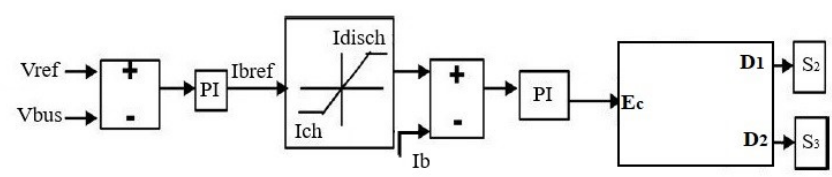

Fig.7 Modelling of battery controller reference $\left(I_{\text {bref }}\right)$ of the inner loop. The reference value is limited by the charging $\left(I_{c h}\right)$ and discharging current $\left(I_{\text {disch }}\right)$ rating that is obtained from the datasheet for safety reason. The error between the reference and battery current $\left(I_{b}\right)$ is applied to PI regulator. The output signal is the duty cycles $\mathrm{D}_{1}$ and $\mathrm{D}_{2}$ for transistors $\mathrm{S}_{2}$ (buck mode) and $\mathrm{S}_{3}$ (boost mode), respectively.

A power management strategy is illustrated by the flow chart in Fig. 8. The CAES system controlled by an MPPT controller is assumed as the main energy source of the hybrid system. The difference between the generated and demand powers is calculated as:

$$
P_{\text {diff }}=P_{C A E S}-P_{\text {dem }}
$$

where $P_{C A E S}$ is the power generated by the CAES and $P_{d e m}$ is the power demand. When $P_{C A E S}$ is greater than $P_{\text {dem }}$ the battery will be charged by the amount of the excess power. In contrast, the battery will be used to supply the power if $P_{C A E S}$ is smaller than $P_{d e m}$.

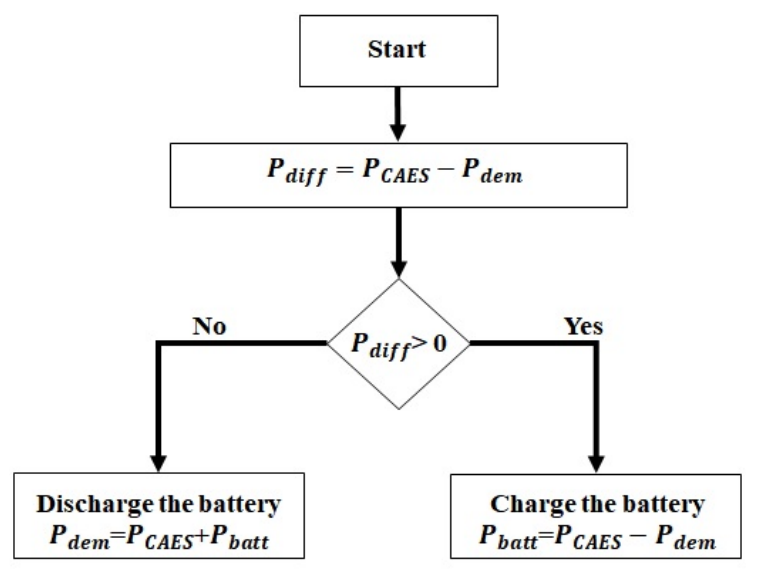

Fig.8 Power management flowchart

\section{STORAGE SIZING}

To estimate the air motor and the battery sizes, An average household load demand for a typical home in the County of Hampshire and the Isle of Wight is used as a case study reported in [13]. The CAES system is assumed a primary source and discharges constantly under isothermal process condition. The operating pressure of 20 bar is selected in this paper. The different power ratings of the air motor are used to estimate properly the air motor and battery sizing. When the power demand is greater than the CAES power, the difference between $P_{C A E S}$ and $P_{\text {dem }}$ called energy deficit $(E D)$ is used for battery sizing. The battery needs to compensate for insufficient power to satisfy the power demand. The battery must cover the energy deficit (ED):

$$
E D(t)=\int\left(P_{C A E S}(t)-P_{d e m}(t)\right) \cdot d t
$$

where $P_{\text {CAES }}(t)<P_{\text {dem }}(t)$ at time $t$. All system models in this paper are implemented using the MATLAB/Simulink. The details of the system parameters are listed in Table I. 
TABLE I. THE SYSTEM PARAMETERS

\begin{tabular}{|c|c|}
\hline \multicolumn{2}{|l|}{ DC generator } \\
\hline Generator armature resistance, $r_{a g}$ & $0.484 \Omega$ \\
\hline Inductance of the generator, $\mathrm{L}_{\mathrm{ag}}$ & $585 \mu \mathrm{H}$ \\
\hline Torque constant, $\mathrm{K}_{\mathrm{e}}$ & 0.0691 N.m/A \\
\hline Back EMF constant, $\mathrm{K}_{\mathrm{m}}$ & $0.121 \mathrm{~V} . \mathrm{s} / \mathrm{rad}$ \\
\hline Total moment of inertia, $\mathrm{J}_{\mathrm{t}}$ & $2.20407 \times 10^{-4} \mathrm{~kg} \cdot \mathrm{m}^{2}$ \\
\hline Viscous friction coefficients, $B_{t}$ & $2.98 \times 10^{-4}$ N.m.s/rad \\
\hline \multicolumn{2}{|l|}{ DC-DC converter } \\
\hline Inductance, L & $5 \mathrm{mH}$ \\
\hline Capacitance, $\mathrm{C}$ & $3500 \mu \mathrm{F}$ \\
\hline MOSFET switching frequency, $f_{s}$ & $100 \mathrm{kHz}$ \\
\hline \multicolumn{2}{|l|}{ Air storage tank } \\
\hline Pressure, $\mathrm{P}$ & $10-30 \mathrm{bar}$ \\
\hline Temperature, $\mathrm{T}$ & $298 \mathrm{~K}$ \\
\hline Specific gas constant, $R_{g}$ & $287 \mathrm{~J} /(\mathrm{kg} . \mathrm{K})$ \\
\hline DC output voltage, $\mathrm{V}$ & $230 \mathrm{~V}$ \\
\hline \multicolumn{2}{|l|}{ Air motor } \\
\hline$C_{1}$ value & 4156 \\
\hline $\mathrm{C}_{2}$ value & 5487 \\
\hline
\end{tabular}

\section{RESUlts AND DISCUSSION}

To select the air motor and battery sizes, the balance between charging and discharging times need to be considered for the available battery in subsequent cycle. The total charged energy should be greater than the discharging energy ( $E_{\text {Charged }}$ $\geq \mathrm{E}_{\text {Discharged }}$ ). Fig. 9 illustrates $P_{\text {dem }}$ and $P_{C A E S}$ under different air motor power rating. The effect of fluctuation of the power generation when the load change is neglected results in the constant $P_{\text {CAES }}$. Four different air motor power rating of 309 , 422, 486 and $606 \mathrm{~W}$ are chosen. The generated power from the CAES exceeds $P_{d e m}$ at the beginning when the air motor power rating of 309,422 and $486 \mathrm{~W}$. This extra power is used to charge the battery. After that, the load demand power increases resulting in insufficient power supply. In contrast, $P_{C A E S}$ exceeds $P_{\text {dem }}$ (red) considerably at power rating $606 \mathrm{~W}$ (purple). The system needs the large capacity size of the battery for storing this extra power. At the power rate of 486 $\mathrm{W}$ (yellow), the charging time is greater than the discharging

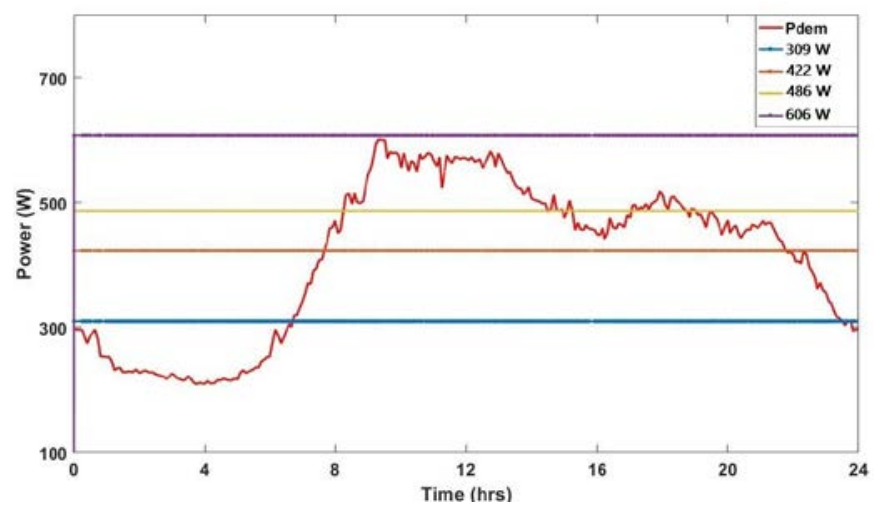

Fig.9 The power rate of the air motor and demand power time of approximately $4.5 \mathrm{hrs}$; the occurrence of charged energy also is greater than that of the discharged energy, and the battery will be ready for the next day. Hence, the air motor with power rating of $486 \mathrm{~W}$ is selected in this study. Since, the CAES system cannot maintain the output voltage, the battery system needs to be estimated for supplying the power deficit. Under the power rate of $486 \mathrm{~W}$, the calculated ED is illustrated in Fig. 10. The ED increases considerably from time of $8 \mathrm{hrs}$ to around $15 \mathrm{hrs}$ and increases slightly around $17 \mathrm{hrs}$. The charging time, moreover, is greater than the discharging time close to $4.5 \mathrm{hrs}$. The overall deficit reaches approximately 450 Whr within a $24 \mathrm{hrs}$ period, which needs to be supplied by the battery. Including the self-discharge loss of $3 \%$ and the discharge efficiency of $95 \%$, therefore, a $500 \mathrm{Whr}$ Li-Ion battery is selected in this study. Note that the effects from the temperature are not considered here.

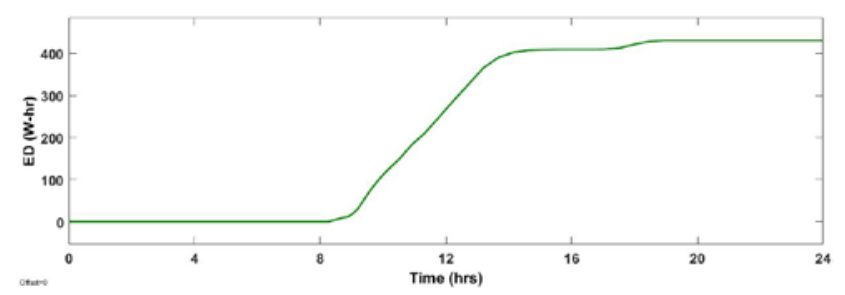

Fig.10 The deficit energy supply

\section{A. Performance of the system}

The following results are obtained for an assumed pressure of 20 bar. Fig. 11 shows the ideal load power demand profile, which is used to investigate the hybrid performance. The output voltage in this simulation is $230 \mathrm{~V}$. The air motor speeds of the CAES system controlled by the MPPT controller are shown in Fig. 12. In the models, the red line is the reference speed generated by the MPPT algorithm while the actual speed is the blue line. The controller regulates the speed of the air motor effectively for real-time tracking that provides the speed reference to control the air motor speed reaching MPP.

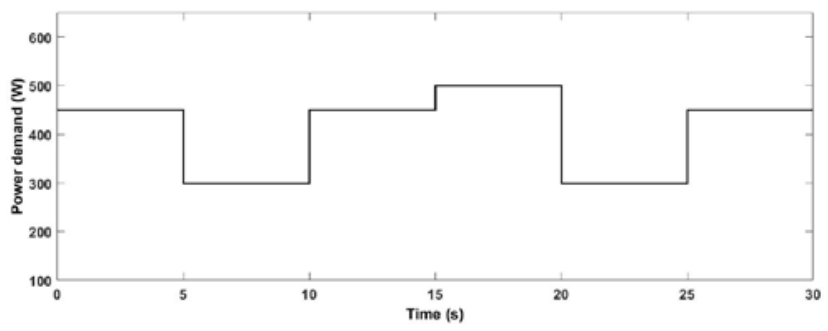

Fig.11 Load power demand

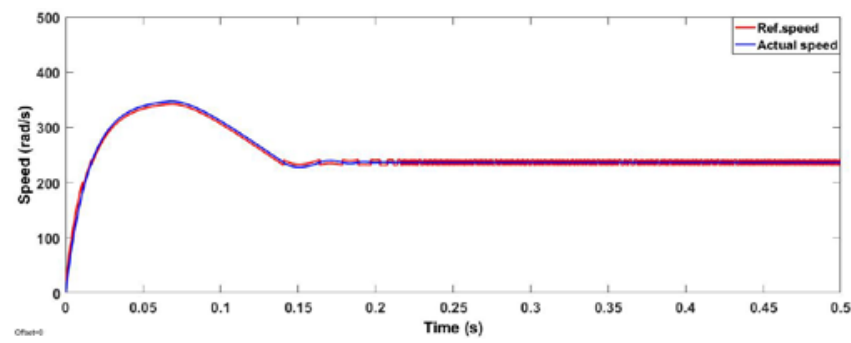

Fig.12 Result of MPPT controller 
When the CAES system is controlled by the voltage controller, Fig. 13 illustrates the simulation results of the CAES system without battery, which is controlled by the cascaded voltage controller. In Fig. 13(a), the output power of the CAES system can respond to the power demand but it has fluctuations when the demand changes. The output voltage in Fig. 13(b) has a long settling time before maintaining the reference voltage. Moreover, because of the voltage controller, the speed of the air motor will vary depending on the power demand; it does not operate at the maximum power point.

Unlike the hybrid battery and CAES system, Fig. 14 shows the simulation results of the hybrid system. In Fig. 14(a), the output power of the hybrid system is matched

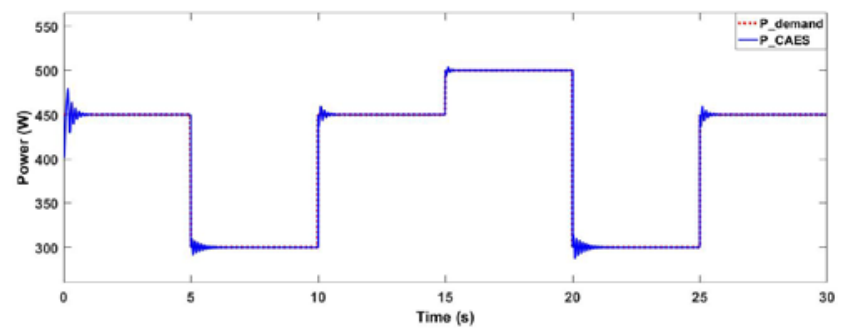

(a) The output power

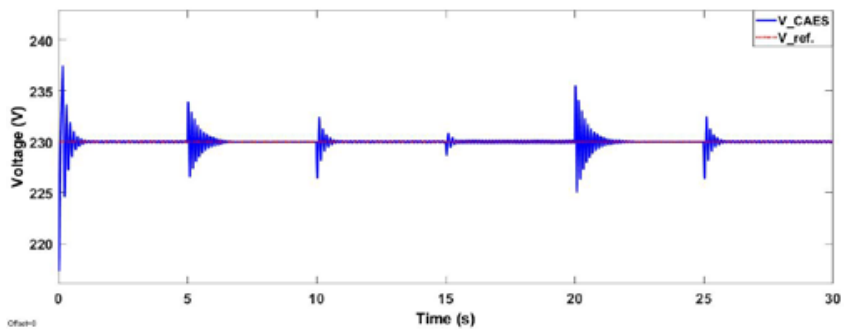

(b) The output voltage

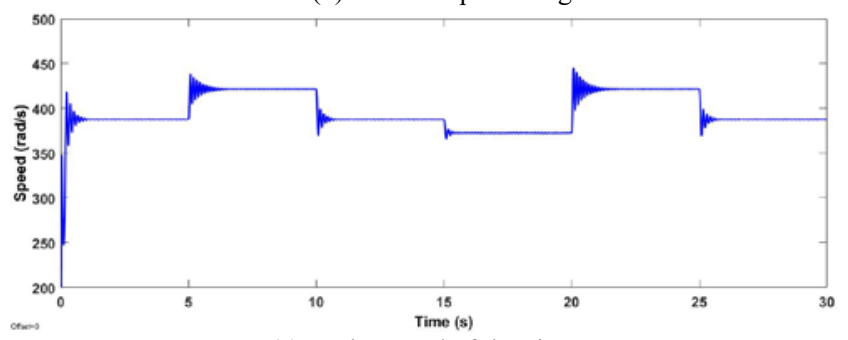

(c) The speed of the air motor

Fig.13 The simulation results of the CAES only system controlled by voltage controller

acceptably with the power demand. The battery-bidirectional converter is able to maintain the output voltage at $230 \mathrm{~V}$ throughout the simulation period presented in Fig. 14(b). Additionally, the battery is charged (shown with negative current) when the CAES power is greater than the load power demand and discharged otherwise (shown with positive current).

Considering the efficiency of the air motor controlled by the different controller, Fig. 15 shows the efficiency of the air motor controlled by three different controllers. The condition for efficiency testing is that the air motor operates at the constant pressure of $20 \mathrm{bar}$, which supplies the power to the constant resistive load. The result shows clearly that the highest efficiency can be achieved when the MEPT controller is used to control the air motor. On the other hand, the air motor controlled by voltage controller has low efficiency although the output voltage is constant. This might results in the power loss in the air motor. The hybrid CAES and battery

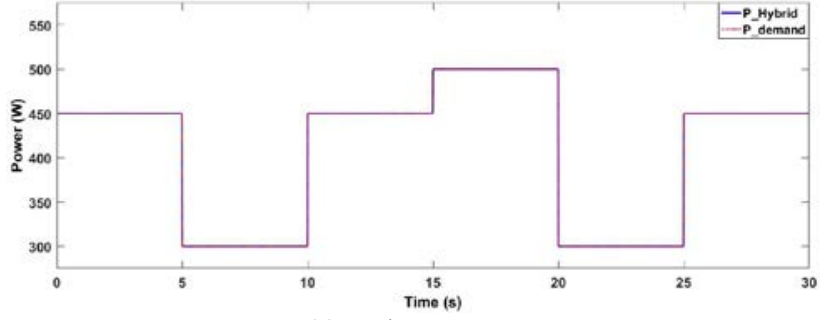

(a) The output power

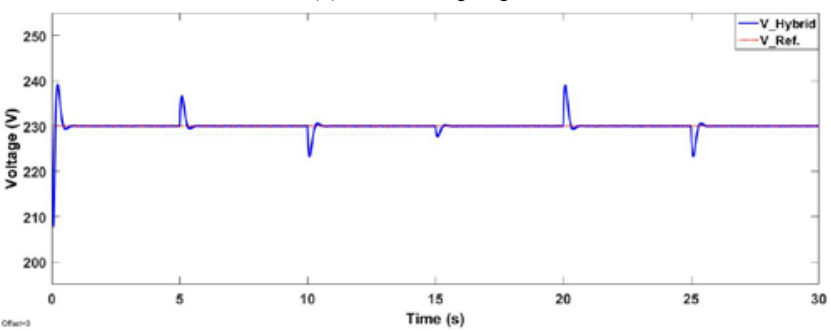

(b) The output voltage

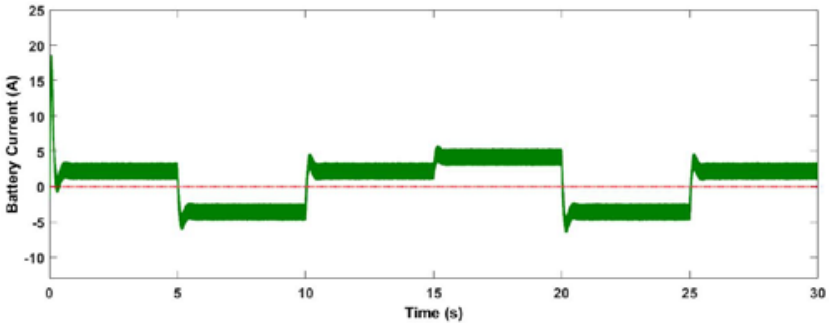

(c) The battery current

Fig.14 The simulation results of the hybrid battery and CAES system

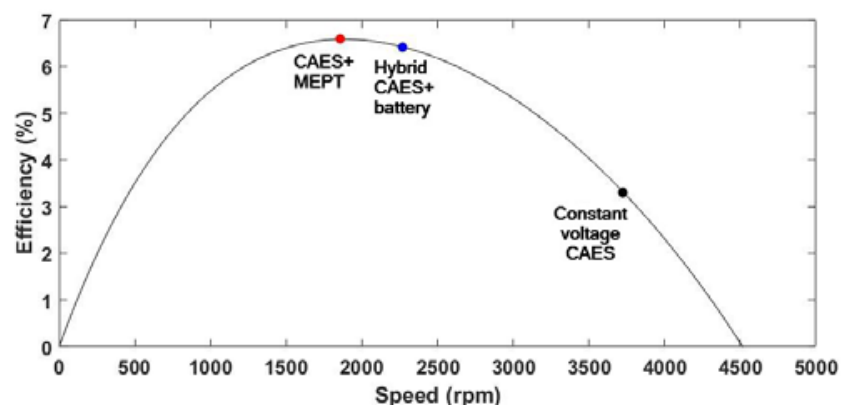

Fig.15 Result of MPPT controller

can recover this situation since the CAES system controlled by MPPT controller operates at the MPP, which is close to the MEP, while the battery controlled by the voltage controller deals with the load fluctuation for maintaining the output voltage. This hybrid system can improve around $47.1 \%$ of the air motor efficiency better than that of the air motor controlled in the voltage mode.

\section{CONCLUSION}

This paper presents the air motor sizing, battery sizing and controller design for a hybrid CAES system with a battery. The sizing methods of both the CAES air motor and the battery are presented for the load power profile in the southern area of the UK. The estimated sizes for both energy storage systems guarantee sufficient energy storage for supplying the power within 24 hours. Two scenarios are illustrated. Controlled in voltage mode is around $47 \%$ lower than that of CAES controlled in MPPT mode. The hybrid system can maintain the voltage when operating at MPP, which improves the performance of the CAES system. With the load changes, the performance of the CAES system is improved by 
including a battery maintaining the voltage when the air motor operates at the MPP. The battery is charged during the low power demand and is discharged otherwise. However, as the CAES and the battery are the energy storage system, there is the capacity limitations of both, which need to be recharged for the next use. The longer sustainability of power supply such as wind and solar energies are considered to connect to these systems in order to store the excess energy. Note that cost effectiveness is outside the scope of this paper.

Future work is required to consider the connection of longer sustainability of power supply such as solar energy and how the CAES is recharged.

\section{ACKNOWLEDGEMENTS}

The authors would like to thank the Royal Thai Navy for their financial support.

\section{REFERENCES}

[1] T. M. I. Mahlia, T. J. Saktisahdan, A. Jannifar, M. H. Hasan, and H. S. C. Matseelar, "A review of available methods and development on energy storage; Technology update," Renew. Sustain. Energy Rev., vol. 33, pp. 532-545, 2014.

[2] H. Chen, T. N. Cong, W. Yang, C. Tan, Y. Li, and Y. Ding, "Progress in electrical energy storage system: A critical review," Prog. Nat. Sci., vol. 19, no. 3, pp. 291-312, 2009.

[3] X. Luo, J. Wang, M. Dooner, and J. Clarke, "Overview of current development in electrical energy storage technologies and the application potential in power system operation," Appl. Energy, vol. 137, pp. 511-536, 2015.

[4] V. Kokaew, "Maximum Power Point Tracking of a Small-Scale Compressed Air Energy Storage System," University of Southampton, 2016.
[5] G. Venkataramani, P. Parankusam, V. Ramalingam, and J. Wang, "A review on compressed air energy storage - A pathway for smart grid and polygeneration," Renew. Sustain. Energy Rev., vol. 62, pp. 895-907, 2016.

[6] M. Budt, D. Wolf, R. Span, and J. Yan, "A review on compressed air energy storage: Basic principles, past milestones and recent developments," Appl. Energy, vol. 170, pp. 250-268, 2016.

[7] D. Villela et al., "Compressed-air energy storage systems for stand-alone off-grid photovoltaic modules," Conf. Rec. IEEE Photovolt. Spec. Conf., pp. 962-967, 2010.

[8] J. Wang et al., "Overview of compressed air energy storage and technology development," Energies, vol. 10, no. 7, 2017.

[9] S. Lemofouet, "Investigation and optimisation of hybrid electricity storage systems based on compressed air and supercapacitors," vol. 3628, p. 11, 2006.

[10] Atlas Copcp, “Atlas Copco," 2016. [Online]. Available: https://webbox.atlascopco.com/airmotor/airmotor.html. [Accessed: 05-Jun-2018].

[11] I. The MathWorks, "SimPoweSystems Blocks, Battery," 2016. [Online]. Available:

https://uk.mathworks.com/help/physmod/sps/powersys/ref/batter y.html. [Accessed: 23-Jul-2018]

[12] V. Kokaew and S. M. Sharkh, "A Hybrid Method for Maximum Power Tracking of a Small Scale CAES System,” pp. 61-66, 2014.

[13] A. Rushby, Thomas W and Anderson, Ben and James, P. A. B. and Bahaj, "Solent Achieving Value from Efficiency (SAVE): randomised control trial household electricity demand data 2017 2018.[Data Collection]," Southampton, 2019. 